\title{
Assessment of correlation between asthenozoospermia and mitochondrial DNA mutations in Egyptian infertile men
}

\author{
Mohamed M. Abd Elrahman', Aida I. El makawy ${ }^{1 *}$ (D, Mohamed S. Hassanane', Sally S. Alam', \\ Nagwa H. A. Hassan² and Medhat K. Amer ${ }^{3}$
}

\begin{abstract}
Background: Asthenozoospermia is a chief reason for male seminal pathologies with an impression of around 19\% of infertile patients. Spermatozoa mitochondrial DNA variations seem to link with low sperm motility. The objective of the study was to assess the relation between mitochondrial mutations and male sterility, especially in asthenozoospermia. The patient semen samples were investigated by studying the sperm physical characters; motility, viability, and morphological parameters were then classified into normozoospermia and asthenozoospermia. In addition, the level of malondialdehyde (MDA) as a bio-indicator of lipid peroxidation, seminal fructose, and total antioxidant capacity (TAC) were estimated. For molecular analysis, DNA from the semen samples was extracted using a DNA extraction kit. ND1, ND2, and ATPase6 genes were amplified by using a specific primer. After the purification procedure, each PCR product was sequenced to identify the single nucleotide polymorphisms (SNPs) in selected genes.
\end{abstract}

Results: A significant negative correlation between seminal plasma malondialdehyde levels and sperm motility was detected. Meanwhile, TAC analysis revealed significantly lower activity $(p \leq 0.05)$ in the sample of asthenozoospermic than in normozoospermic men. As regards the seminal plasma fructose, there was no significant difference in the fructose level of normozoospermia and asthenozoospermia cases. At the molecular level, 31 diverse nucleotide substitutions were recognized in mitochondrial DNA. Only ten (10) mutations led to amino acid transformation: four have deleterious effects, four are benign, and the other two have conflicting effectiveness.

Conclusions: This study is the first in Egypt that is concerned with studying the relationship between the mitochondrial DNA mutations in human spermatozoa of asthenozoospermic patients and fertility. The results displayed scientific indications evidenced that there is an association between mitochondrial mutations and male infertility.

Keywords: Male fertility, mtDNA, Mutations, Sperm motility, ROS, Lipid peroxidation

\footnotetext{
*Correspondence: aelmakawy@yahoo.com

${ }^{1}$ Cell Biology Dept. , Division of Genetic Engineering and Biotechnology Research, National Research Centre, 33 El Bohouth St., Dokki, P.O.12622, Giza,

Egypt

Full list of author information is available at the end of the article
}

( ) The Author(s). 2021 Open Access This article is licensed under a Creative Commons Attribution 4.0 International License, which permits use, sharing, adaptation, distribution and reproduction in any medium or format, as long as you give appropriate credit to the original author(s) and the source, provide a link to the Creative Commons licence, and indicate if changes were made. The images or other third party material in this article are included in the article's Creative Commons licence, unless indicated otherwise in a credit line to the material. If material is not included in the article's Creative Commons licence and your intended use is not permitted by statutory regulation or exceeds the permitted use, you will need to obtain permission directly from the copyright holder. To view a copy of this licence, visit http://creativecommons.org/licenses/by/4.0/. 


\section{Background}

Male infertility denotes male's incapability to cause fertile female pregnancy. It affects around $7 \%$ of men all over the world [1]. Male sterility is generally owed to semen shortages, and semen integrity is deemed as a replacement measure of fecundity [2]. The utmost mutual reason for male infertility is idiopathic. Oxidative stress would show an energetic character in the etiology of male infertility as a result of its targeting to spermatozoa plasma membrane a polyunsaturated fatty acid [3].

Sperm motility is an imperative determinant of fertility, where it is a public feature of flagellate spermatozoa and is an important sperm characteristic for the process of fertilization [4]. Asthenozoospermia is a chief reason for male seminal pathologies that impact around 19\% of infertile patients. It is characterized by decreasing progressively motile percentage (PR) spermatozoa under $32 \%$ [5]. Spermatozoa motility is very reliant on numerous metabolic pathways and regulatory mechanisms. Further, the specific gene defect association and any deformities of these factors could be accountable for poor sperm motility and accordingly sterility [6]. Motility is an energetic trait of spermatozoa for positive fertilization that is essential for passage through the female genital tract to penetrate the oocyte zona pellucida. Sperm motility is the origin of the sperm tail flagella movement by ATP-derived energy, formed in the mid-piece positioned mitochondrion [7].

Human mitochondria perform a crucial role in energy manufacture for all organisms through the synthesis of adenosine triphosphate (ATP) in oxidative phosphorylation. Sperm mitochondria are an industrial unit for energy production via oxidative phosphorylation (OXPHOS), viz ATP synthesis, and they play crucial roles in spermatogenesis, differentiation, and functioning of germ cells [8]. The spermatozoon of a mammal contains between 22 and 75 mitochondria situated in the intermediate piece of the flagellum, ensuring correct flagellar function and sperm motility that deem as a vital parameter for fertilizing capacity [9].

The mitochondrial DNA genes lack introns and intergenic non-coding nucleotides $[10,11]$. The mtDNA repair system does exist and not enough to overcome the oxidative damage continued by the mitochondrial genome as a result of the closeness to the respiratory chain complexes in the mitochondrial membrane (MIM) which generate ROS. Therefore, the range of mtDNA mutation is considerably high (10-17-fold higher) compared to nuclear DNA [10,12]. The mtDNA mutations can deteriorate the energy creation and the organism's health, as proteins encoded in the mtDNA are the basics of the OXPHOS [13]. Mutations within mtDNA may cause the beginning of mitochondrial diseases, which are a major group of genetic disorders $[14,15]$.
The human sperm mitochondrial ultrastructure defects appear to link with low sperm motility [16]. Earlier work has discovered that mtDNA variations which impact cellular homeostasis may give rise to reduce fertility [17]. Also, Jodar et al. [18] advised that the alteration in the specific mRNA's transcripts in sperm cells of Asthenozoospermic patients arise along with mitochondrial protein nuclear-encoded transcripts. Numerous studies have itemized links between mitochondrial genetic variation and deleterious male reproductive outcomes. They suggest that the progress of compensatory mechanisms is partially active in offsetting the male-harming mtDNA mutations effects. Additionally, there seems to be a sex bias developing in the reporting of such effects, by many studies proposing that different mtDNA variants affect constituents of male fertility [19-21].

The SNPs happened when errors occur (substitution, insertion, and deletion), and they are prominent sources of variation in the human genome and aid as excellent genetic markers for constructing high genetic maps and to carry out association studies related to diseases. Most SNPs are situated in non-coding regions of the genome and have no direct identified impact on the phenotype of an individual, but their character till now stays elusive, and liable on where SNPs happen; it might have unlike consequences at the phenotypic level [22]. Many studies reported that there is an association between the presence of mitochondrial DNA (mtDNA) variation and infertility in the Tunisian [23], Jordanian [24], and Iranian [25] populations.

The current study is considered the first study in the Egyptian population concerning mitochondrial DNA (mtDNA) variation, especially in asthenozoospermic patients. The work was planned to evaluate the relation between the occurrences of the mtDNA mutations (SNPs) in asthenozoospermic patient semen in the ND1, ND2, and ATPase6 genes and the spermatozoa motility.

\section{Methods}

Sample collection and semenological analysis

Human semen samples were obtained from patients with an age ranging from 21 to 45 years at the Adam International Hospital for Reproductive Medicine in Giza, Egypt. Semen samples were collected from 75 patients which included 25 with normal motility value (normozoospermic group) and 50 with pathogenic (asthenzoospermia group) and processed in the laboratory within an hour of ejaculation. Semen was collected by masturbation into sterile disposable containers after $3-5$ days of sexual abstinence and allowed to liquefy for $30-60 \mathrm{~min}$. Then, routine seminal analyses were performed according to the World Health Organization (WHO) guideline [26]. Ethical approval was obtained from the Ethics Committees of the National Research Centre (Approval 
No. 16/455), and informed consent was obtained from all subjects.

The liquefaction characteristics of the semen are examined $20 \mathrm{~min}$ after ejaculation and recorded. All samples were assessed according to World Health Organization (WHO) guidelines (2010). The following variables were taken into consideration: ejaculate volume $(\mathrm{ml})$, sperm concentration $\left(10^{6} / \mathrm{ml}\right)$, total sperm number $\left(10^{6} /\right.$ ejaculate), progressive motility (\%), morphology (\% abnormal forms), and leukocyte concentration $\left(10^{6} / \mathrm{ml}\right)$. Semen samples with leukocytospermia and/or increased viscosity were excluded from this study. A sperm viability test was carried out to differentiate cell death from immotility by staining with eosin Y $0.5 \%$ in saline solution. These samples were divided into two groups on the basis of their progressive motility, using the WHO 2010 5th percentile as the cutoff: the asthenozoospermic group comprises samples with progressive motility< $32 \%$, and the normozoospermic group comprises samples with progressive motility $\geq 32 \%$.

\section{Measurement of lipid peroxidation}

Malondialdehyde levels were determined by the malondialdehyde (MDA)-thiobarbituric acid (TBA) test which is the colorimetric reaction of MDA and TBA in acid solution. TBA reacted with MDA, a secondary product from lipid peroxidation, which generated an adduct of red color, which was detected spectrophotometrically [27].

\section{Measurement of fructose in semen}

The fructose measurement may help in assessing the diagnosis and the management of male infertility. Fructose seminal concentration has negative correlations with sperm concentration and motility [28]. Fructose was measured according to the protocol of Foreman et al. [29], which forms a pink color when heated with resorcinol in the presence of hydrochloric acid, which can be directly measured photometrically.

\section{Measurement of total antioxidant capacity}

The determination of the total antioxidant capacity is performed by the reaction of antioxidants in the sample with a defined amount of exogenously provide hydrogen peroxide $\left(\mathrm{H}_{2} \mathrm{O}_{2}\right)$ according to the protocol of Koracevic et al. [30]. The antioxidants in the sample eliminate a certain amount of the provided hydrogen peroxide. The residual $\mathrm{H}_{2} \mathrm{O}_{2}$ is determined calorimetrically by an enzymatic reaction which involves the conversion of 3,5, dichloro-2-hydroxybenzensulphonate to a colored product according to the manufacturer's instruction.

\section{Extraction of total DNA and quantification}

The total DNA from the sperm cells was isolated using the QIAamp DNA Mini kit (QIAGEN) as per the manufacturer's instruction: https://www.qiagen.com. Three microliters of the extracted DNA and $2 \mu \mathrm{l}$ of DNA gel loading dye $(6 \times)$ were mixed then loaded in a $1.5 \%$ agarose gel to determine the integrity of DNA, and electrophoresis was carried out at $100 \mathrm{~V} / \mathrm{cm}$ for $30 \mathrm{~min}$. The photograph was examined below UV light by a gel documentation imaging system (Bio-Rad, USA). The extracted DNA was quantified using the NanoDrop Lite Spectrophotometer (Thermo Scientific).

\section{Polymerase chain reaction analysis}

The ND1, ND2, and ATPase 6 mitochondrial genes are amplified using 2 sets of designed PCR primers, which were located in the flanking regions of each gene as illustrated in Table 1. For facilitating the work, a master mix was usually prepared first, and $18 \mu \mathrm{l}$ from this mix was dispersed in the 0.2-ml Eppendorf tube and $2 \mu \mathrm{l}$ from the template DNA is added. The master mix formula was as in Table 2. The conditions of PCR amplification were as follows: a denaturation step at $94{ }^{\circ} \mathrm{C}$ for 5 min followed by 35 cycles at $94{ }^{\circ} \mathrm{C}$ for $1 \mathrm{~min}$, annealing for $1 \mathrm{~min}$ (the annealing temperature varied depending on the primer size, length of amplified fragment, "GC" content, and the structure of DNA fragment (Table 1)) and $72{ }^{\circ} \mathrm{C}$ for $1 \mathrm{~min}$ and then a final extension at $72{ }^{\circ} \mathrm{C}$ for $5 \mathrm{~min}$ and stop at $4^{\circ} \mathrm{C}$ [31].

\section{Gene sequence analysis}

The sequencing was done by Macrogen Incorporation (Seoul, Korea) after the purification procedure was done by using a Thermo Scientific purification kit of PCR product. The variants were imported into the BioEdit sequence alignment editor version 7.2.1 and aligned with the reference human mtDNA where the mutations at various points were identified and recorded.

\section{Polymorphisms screening}

The DNA sequence variations were determined by alignment of study gene sequence against database sequences using nBLAST tool https://blast.ncbi.nlm.nih.gov/Blast. cgi. These sequences were compared to the reference sequence (accession number: NC_012920.1). Mutation type (synonymous or non-synonymous) sequence translated to amino acid was determined by the Expasy program https://web.expasy.org/translate/. The single nucleotide polymorphisms (SNPs) were detected within 15 samples, 7 of normozoospermia and 8 for asthenozoospermia by the mitomap software http://www. mitomap.org to differentiate between old mutation and new (novel) SNPs. Analysis of the effect of the nonsynonymous mutations was done by the SIFT and 
Table 1 Primer pairs used to amplify study genes

\begin{tabular}{|c|c|c|c|c|c|}
\hline Primer name & Genomic location (bp) & Sequence $\left(5^{\prime}-3^{\prime}\right)$ & GC content (\%) & Annealing temp. & Product size (bp) \\
\hline $\begin{array}{l}\text { ND1 F } \\
\text { ND1 R }\end{array}$ & $\begin{array}{l}3245-3264 \\
4370-4351\end{array}$ & $\begin{array}{l}\text { CCCCGGTAATCGCATAAAACT } \\
\text { TITGGATTCTCAGGGATGG }\end{array}$ & $\begin{array}{l}45 \\
45\end{array}$ & $\begin{array}{l}660 \mathrm{C} \\
660 \mathrm{C}\end{array}$ & 1125 \\
\hline $\begin{array}{l}\text { ND2 F } \\
\text { ND2 R }\end{array}$ & $\begin{array}{l}4382-4402 \\
5565-5545\end{array}$ & $\begin{array}{l}\text { CCTATCACACCCCATCCTAAA } \\
\text { TGCAACTTACTGAGGGCTITG }\end{array}$ & $\begin{array}{l}47 \\
47\end{array}$ & $\begin{array}{l}690 C \\
690 C\end{array}$ & 1183 \\
\hline $\begin{array}{l}\text { ATPase6 F } \\
\text { ATPase6 R }\end{array}$ & $\begin{array}{l}8531-8552 \\
9185-9206\end{array}$ & $\begin{array}{l}\text { AAC GAA AAT CTG TTC GCT TCA } \\
\text { ATG TGT TG T CGT GCA GGT GA }\end{array}$ & $\begin{array}{l}47 \\
47\end{array}$ & $\begin{array}{l}690 C \\
690 C\end{array}$ & 675 \\
\hline
\end{tabular}

$F$ forward primer, $R$ reverse primer, $b p$ base pair position related to the reference human mitochondrial sequence (accession number NC_012920.1)

PROVEAN software. SIFT relies on sequence homology in order to sort intolerant from tolerant mutations http://sift.jcvi.org/. Additionally, the PROVEAN software is a sequence-based predictor that estimates whether a protein sequence variation affects protein function or not http://provean.jcvi.org.

\section{Statistical analysis}

The Statistical Package for the Social Sciences (SPSS) 20.0 (SPSS, Inc., Chicago, USA) was used for the statistical analysis. Continuous variables for each group of patients were expressed as mean \pm standard error of the mean. The statistical analysis was conducted by comparing the distribution of each variable of the two study groups using Student's $t$ test, as appropriate. The correlations among the variables were evaluated by calculating Pearson's correlation coefficient. For statistical purposes, $p \leq 0.05$ was considered as significant.

\section{Results}

\section{Semen physical character}

Table 3 illustrates the basic semen characters, sperm concentration, morphological parameters, total motility, and progressive motility percentages of normozoospermic and asthenozoospermia infertile men. The result of the present investigation revealed that the percentages of spermatozoa total and progressive motility were significantly low $(p \leq 0.001)$ in asthenozoospermia infertile men $(21.45 \pm 1.81 ; 5.27 \pm 0.9$, respectively) as compared to those of normozoospermic men $(53.13 \pm 1.91 ; 12.31$ \pm 1.10 , respectively). The sperm count was significantly

Table 2 The values of a master mix components

\begin{tabular}{lll}
\hline Component & Volume $(\boldsymbol{\mu l})$ & Final concentration \\
\hline DNA sample template & 2.0 & $50 \mathrm{ng}$ \\
10X PCR reaction buffer & 2.0 & $1 \times$ \\
Forward primer & 1.5 & $1 \mathrm{pmol}$ \\
Reverse primer & 1.5 & $1 \mathrm{pmol}$ \\
dNTPs & 2.0 & $200 \mu \mathrm{M}$ \\
TaqDNA polymerase & $\mathrm{X}$ & $1 \mathrm{U}$ \\
Sterile double-distilled water & $\mathrm{X}$ & Up to $20 \mu \mathrm{l}$ \\
\hline
\end{tabular}

decreased $(p \leq 0.001)$ in the infertile asthenozoospermic men $(34.27 \pm 8.82)$ than those of the normozoospermic men $(85.83 \pm 14.35)$. Differences between the mean percentages of sperm morphology, teratozoospermia index, and acrosome index of fertile and infertile men (91.3 \pm $1.0,1.4 \pm 0.04$, and $57.8 \pm 3.8$ versus $95.3 \pm 0.6,1.6 \pm$ 0.06 , and $46.7 \pm 3.4$, respectively) were significant at $p \leq$ 0.05 . While no significant difference in the sperm deformative index (SDI) of the two groups.

\section{Semen biochemical results}

Table 4 represents the malondialdehyde, total antioxidant activity, and fructose levels in normozoospermia and asthenozoospermia samples. The level of malondialdehyde (MDA) in the seminal plasma of the asthenozoospermic men was significantly higher $(p \leq 0.01)$ than that in healthy normozoospermic fertile men. The seminal total antioxidant capacity test revealed significantly lower activity in asthenozoospermia $(p \leq 0.05)$ compared to normozoospermia, whereas the results of seminal plasma fructose indicated there was no significant difference in the fructose level of normozoospermia and asthenozoospermia cases.

Our findings showed that there was a negative correlation between motility with MDA levels $(r=-0.082)$, sperm concentration $(r=-0.229)$, and acrosome index $(r=-0.0012)$, while this correlation was positive between motility and total antioxidant capacity $(r=0.098)$, seminal fructose level $(r=0.201)$, and morphology $(r=0.184)$ in the Normozoospermia group as shown in Fig. 1. While

Table 3 physical parameters of normozoospermic and asthenozoospermic men

\begin{tabular}{lll}
\hline Parameters & Normozoospermia & Asthenozoospermia \\
\hline Total motility (\%) & $53.13 \pm 1.91^{* *}$ & $21.45 \pm 1.81$ \\
Progressive motility (\%) & $12.31 \pm 1.10^{* *}$ & $5.27 \pm 0.9$ \\
Sperm count $\left(10^{6}\right)$ & $85.83 \pm 14.35^{* *}$ & $34.27 \pm 8.82$ \\
Sperm morphology (\%) & $91.3 \pm 1.0$ & $95.3 \pm 0.6 \pm 0.6^{*}$ \\
TZI (\%) & $1.4 \pm 0.04$ & $1.64 \pm 0.06^{*}$ \\
Acrosome index (\%) & $57.8 \pm 3.8^{*}$ & $46.7 \pm 3.4$ \\
SDI & $1.71 \pm 0.08$ & $1.85 \pm 0.09$ \\
\hline
\end{tabular}

Values represent as mean $\pm \mathrm{SEM},{ }^{*} p \leq 0.05,{ }^{* *} p \leq 0.01$

$T Z I$ teratozoospermia index, SDI sperm deformative index 
Table 4 Biochemical parameters of seminal plasma

\begin{tabular}{lll}
\hline Parameters & Normozoospermia & Asthenozoospermia \\
\hline MDA $(\mathrm{nmol} / \mathrm{l})$ & $6.02 \pm 0.51$ & $9.89 \pm 0.68^{* *}$ \\
TAC $(\mathrm{mM} / \mathrm{l})$ & $1.81 \pm 0.08^{*}$ & $1.56 \pm 0.07$ \\
Fructose $(\mathrm{mg} / \mathrm{dl})$ & $241.00 \pm 9.57$ & $225.00 \pm 9.47$
\end{tabular}

Values represent as mean $\pm \mathrm{SEM},{ }^{*} p \leq 0.05,{ }^{* *} p \leq 0.01$

MDA malondialdehyde, TCA total antioxidant capacity

there was a negative correlation between motility with MDA levels $(r=-0$. 282), sperm morphology $(r=-0$. 349), TZI $(r=-0.291)$, and acrosome index $(r=-0.005)$ in the asthenozoospermia group. The correlation between motility and sperm concentration $(r=0.0 .408)$, total antioxidant capacity $(r=0.052)$, and seminal fructose level $(r$
$=0.144)$ in the asthenozoospermia group was significantly positive $(p \leq 0.05)$ as illustrated in Fig. 2.

\section{Molecular results}

Amplification of a fragment from the MT-ND1, MTND2, and MT-ATPase genes of human semen samples formed 936, 1183, and $676 \mathrm{bp}$ PCR product, respectively (Fig. 3). The sequence analysis of $M T-N D 1, M T-N D 2$, and MT-ATPase genes in normozoospermia and asthenozoospermia samples revealed the presence of several mutations in different nucleotide positions in genes as illustrated in Table 5. Concisely, 31 diverse nucleotide substitutions were recognized, and most mutations are transitional mutations.

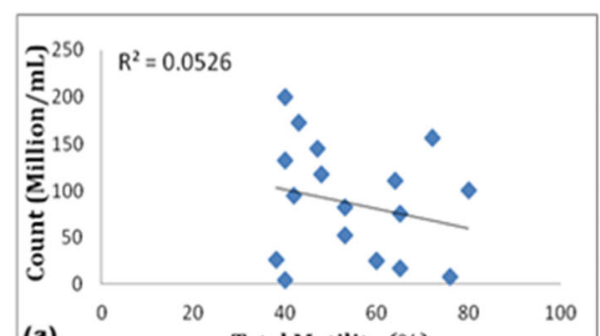

(a)
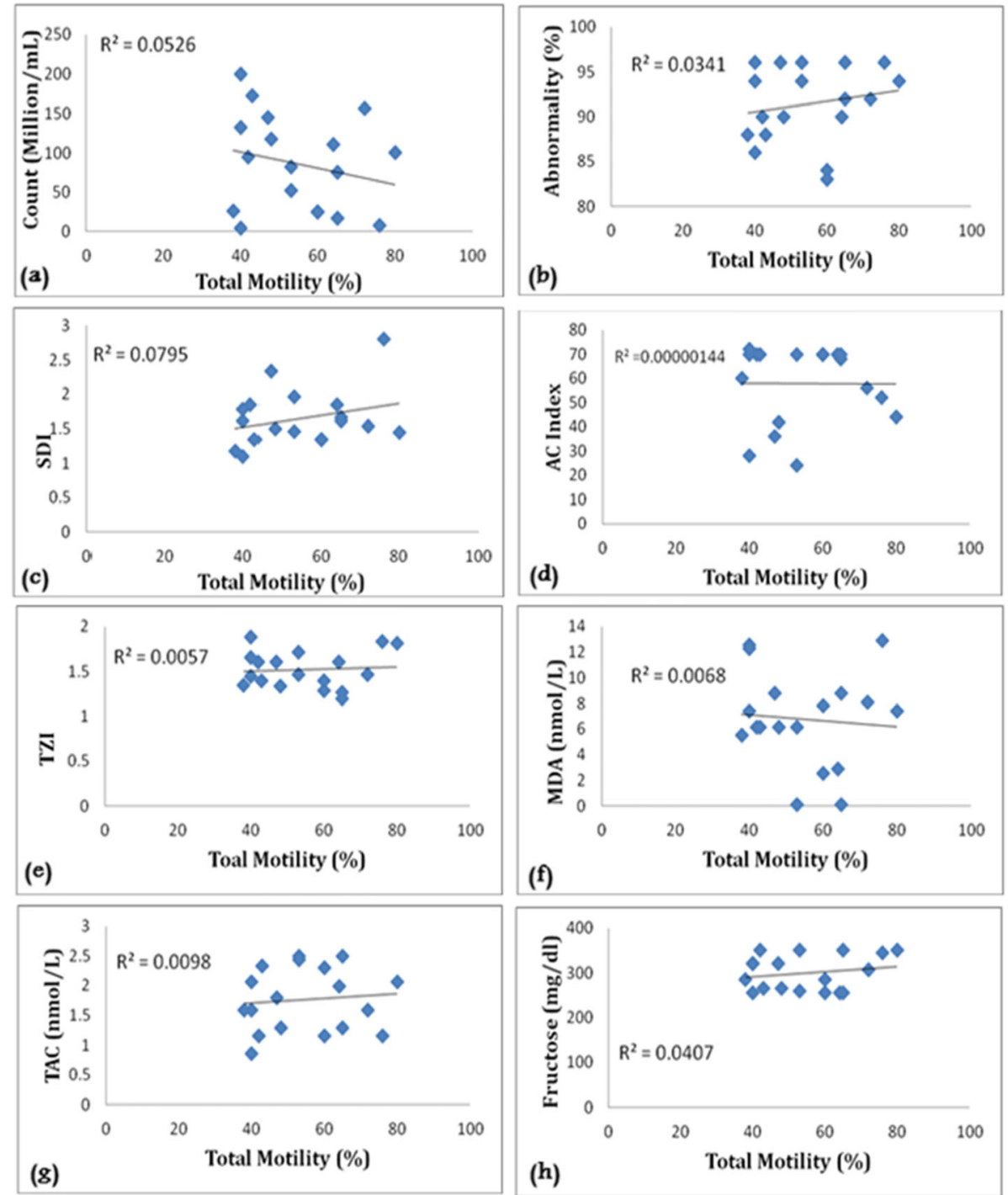

Fig. 1 Correlation coefficient between total motility in the normozoospermia group. a Sperm count. b Abnormality (\%). c Sperm deformative index. d Acrosome index. e Teratozoospermia index. $\mathbf{f}$ Malondialdehyde. $\mathbf{g}$ Total antioxidant capacity. $\mathbf{h}$ Fructose level 

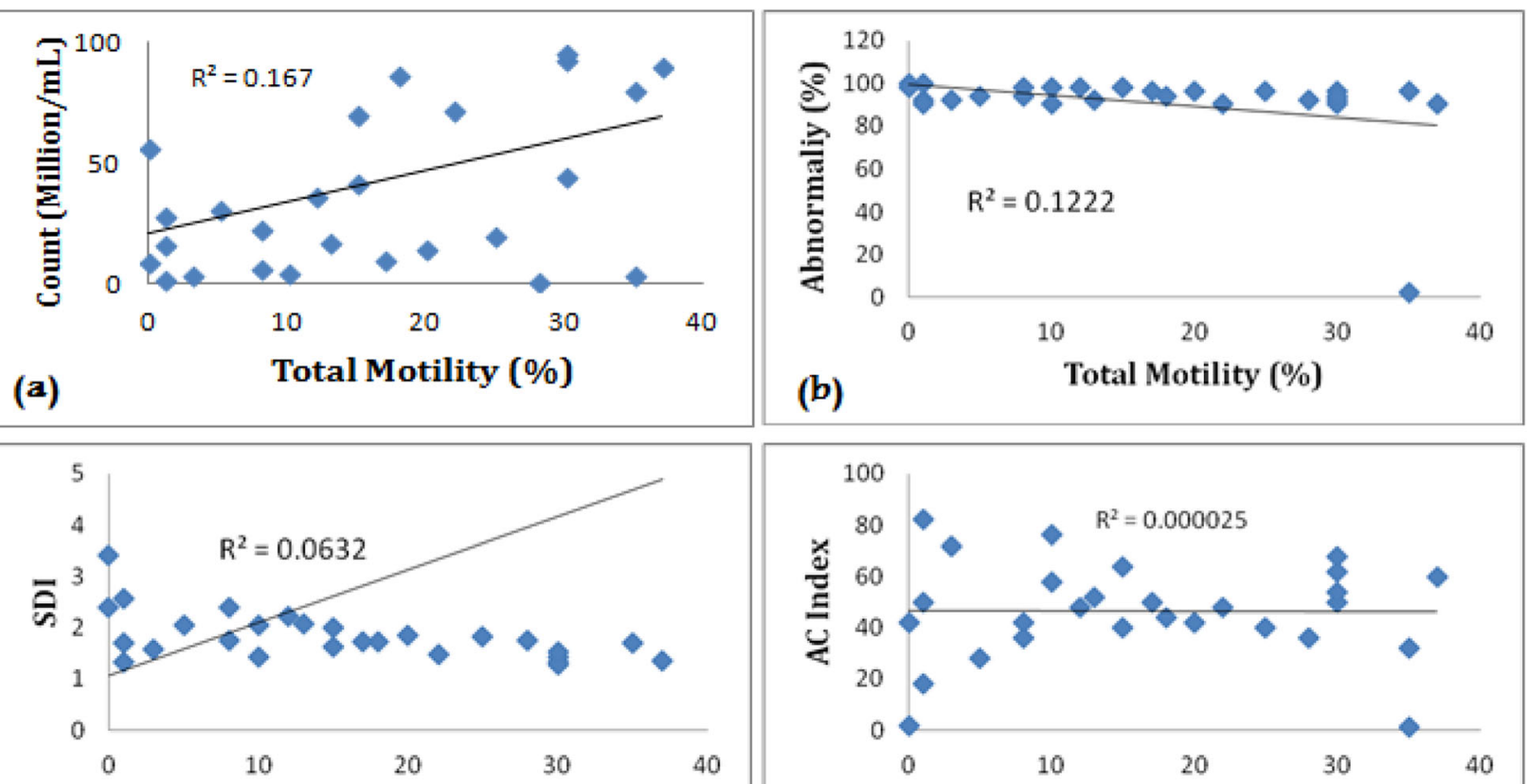

(c)

Total Motility (\%)
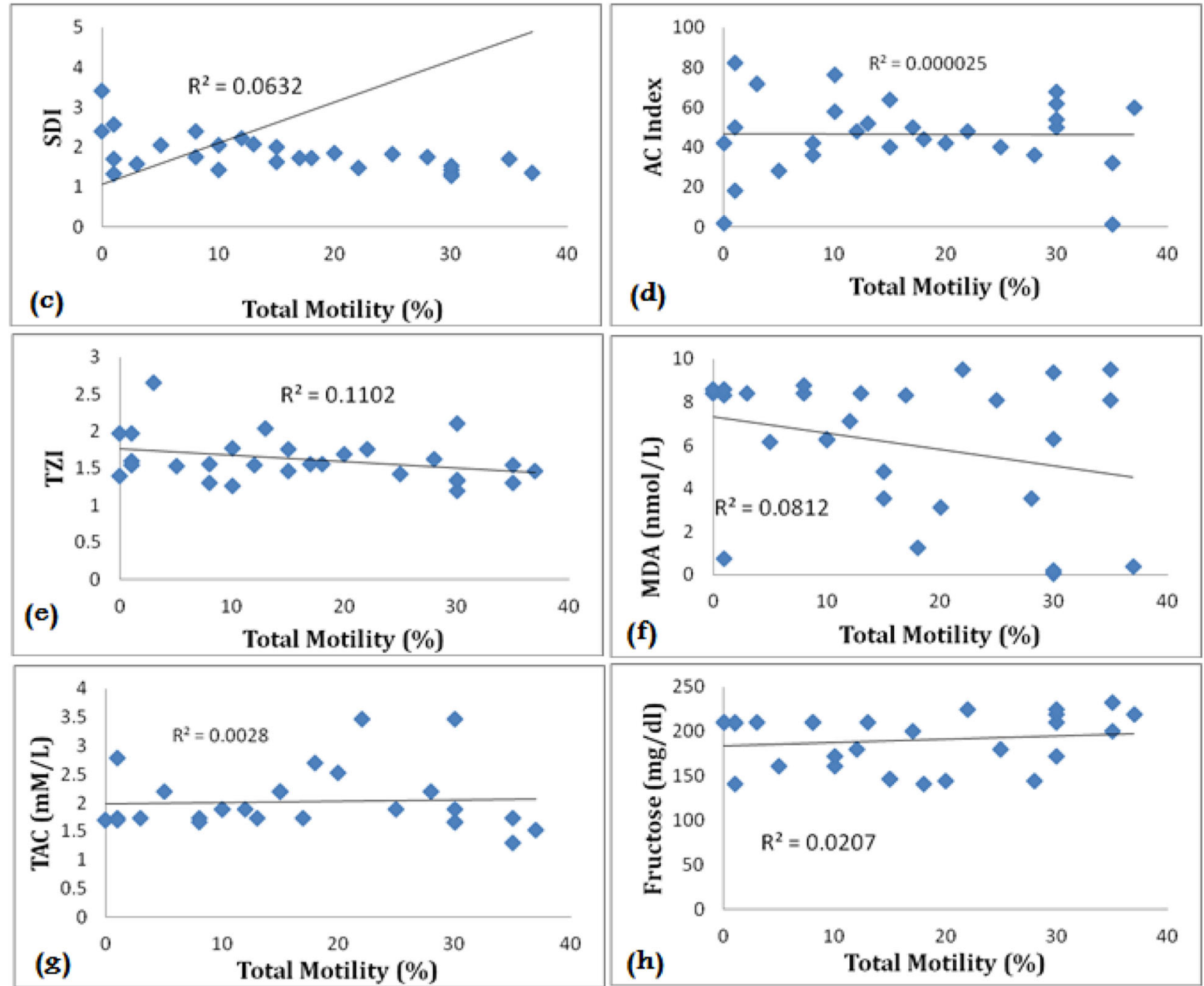

Fig. 2 Correlation coefficient between total motility. a Sperm count. b Abnormality (\%). c Sperm deformative index. d Acrosome index. e Teratozoospermia index. $\mathbf{f}$ Malondialdehyde. $\mathbf{g}$ Total antioxidant capacity. $\mathbf{h}$ Fructose level

Alignment of the sequence of the genes discovered the incidence of twelve point mutations in MT-ND1, one mutation was insertion and the others were of transition type (Fig. 4). The normozoospermia samples yielded four SNPs which were two synonymous mutations at nucleotides A4104G and A4158G, besides two nonsynonymous mutations at positions insertion (T) 4169 and T4216C. Sequence analysis of the ND1 gene in asthenozoospermia samples yielded ten SNPs which were detected, six of which were synonymous mutations at nucleotides T3396C, T3423C, C3594T, G3693A, G3705A, and A4104G, and the others were nonsynonymous mutation at positions T3398C, T3821C, G4048A, and insertion (T) 4169. 


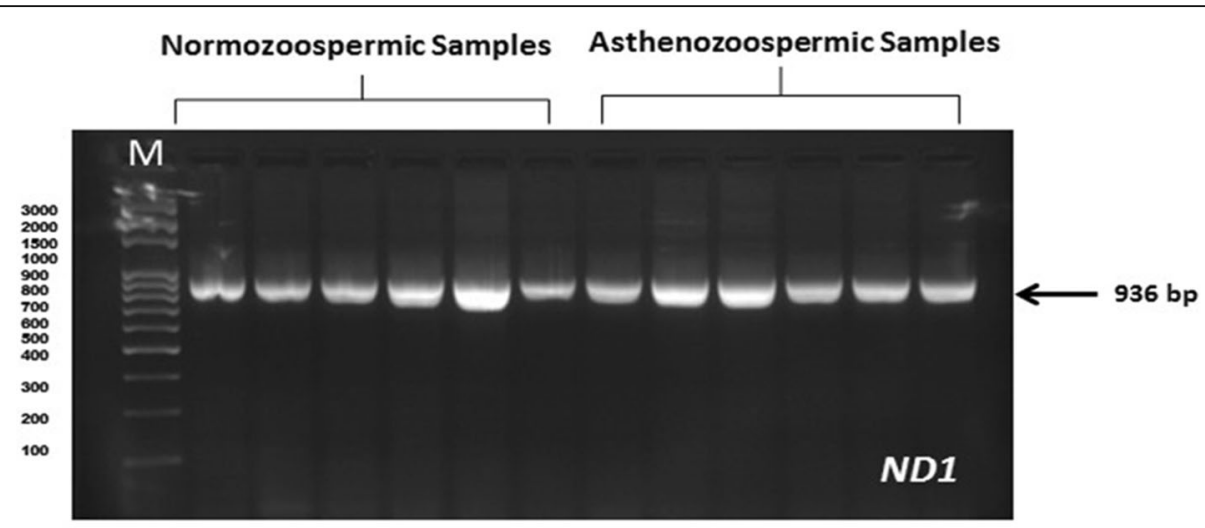

(a)

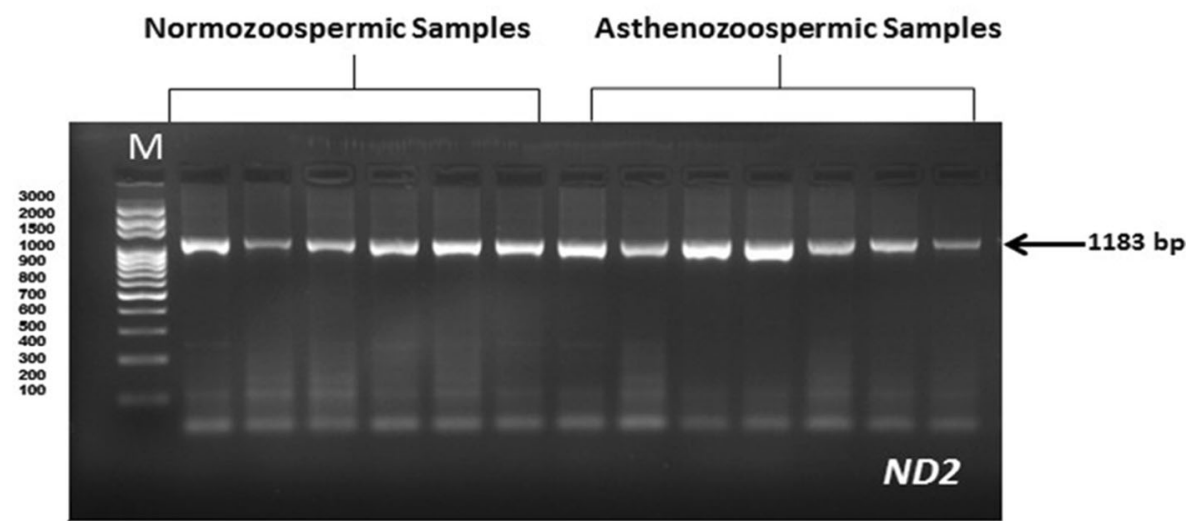

(b)

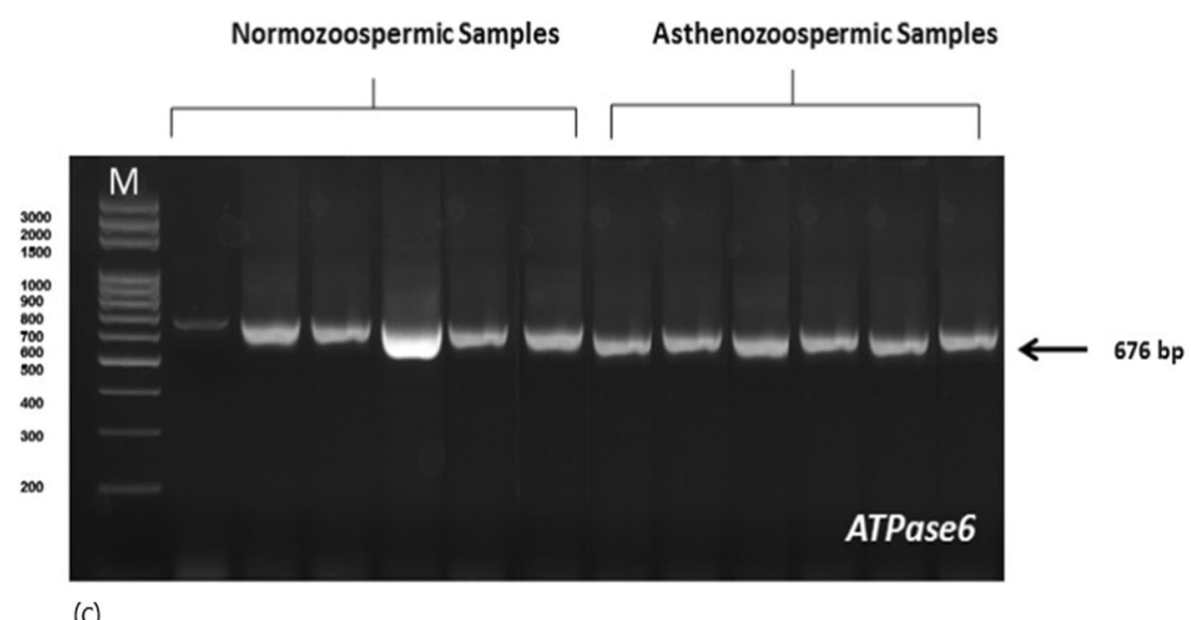

Fig. 3 PCR products. Lane M: lambda DNA marker digested with restriction enzymes; lanes 1-6: normozoospermia samples; lanes 7-12: asthenozoospermia samples. a ND1 gene. b ND2 gene. c ATPase6 gene

In the ND2 gene, fourteen point mutations were characterized (Fig. 5). Sequence analysis of the ND2 gene in mormozoospermia samples yielded nine base substitutions; six of them were synonymous; five are transition A4769G, G4991A, C5027T, G5147A, and A5351G; and one SNP of deletion type at nucleotide number deletion (A) 4613. The other three mutations were nonsynonymous, two are transition at nucleotide positions
A4767G and C5320T, and the latter is of transversion type at nt C5331A. Twelve SNPs were detected in the asthenozoospermic group; ten base substitutions were synonymous while two were non-synonymous at nucleotide numbers A4767G and C5320T. The comparison applied by BioEdit revealed that the seven base substitutions located at nucleotides (nts) deletion (A) 4613, A4767G, A4769G, G4991A, G5147A, C5320T, and A5351G are 
Table 5 The mtDNA mutations identified in the ND1, ND2, and ATPase6 genes

\begin{tabular}{|c|c|c|c|c|c|c|}
\hline Nucleotide position & Nucleotide change & Amino acid change & Mutation in Normo. & Mutation in Astheno. & Frequency (\%) & Mitomap (Y) \\
\hline \multicolumn{7}{|l|}{ ND1 gene } \\
\hline 3396 & $\mathrm{~T}-\mathrm{C}$ & Silent & & 1 & 6.6 & Y \\
\hline 3398 & $\mathrm{~T}-\mathrm{C}$ & $M-T$ & & 1 & 6.6 & $x$ \\
\hline 3423 & $\mathrm{~T}-\mathrm{C}$ & Silent & & 1 & 6.6 & $x$ \\
\hline 3594 & $\mathrm{C}-\mathrm{T}$ & Silent & & 2 & 13.3 & Y \\
\hline 3693 & $\mathrm{G}-\mathrm{A}$ & Silent & & 1 & 6.6 & Y \\
\hline 3705 & $\mathrm{G}-\mathrm{A}$ & Silent & & 2 & 13.3 & Y \\
\hline 3821 & $\mathrm{~T}-\mathrm{C}$ & $L-P$ & & 1 & 6.6 & Y \\
\hline 4048 & $\mathrm{G}-\mathrm{A}$ & $\mathrm{D}-\mathrm{N}$ & & 1 & 6.6 & Y \\
\hline 4104 & $A-G$ & Silent & 1 & 2 & 20.0 & Y \\
\hline 4158 & $A-G$ & Silent & 1 & & 6.6 & Y \\
\hline 4169 & Ins. T & $L-P$ & 1 & 1 & 13.3 & Y \\
\hline 4216 & $\mathrm{~T}-\mathrm{C}$ & $\mathrm{Y}-\mathrm{H}$ & 1 & & 6.6 & Y \\
\hline \multicolumn{7}{|l|}{ ND2 gene } \\
\hline 4613 & Del A & Silent & 1 & 1 & 13.3 & $x$ \\
\hline 4767 & $A-G$ & $M-V$ & 1 & 6 & 46.6 & Y \\
\hline 4769 & $A-G$ & Silent & 1 & 1 & 13.3 & Y \\
\hline 4856 & $\mathrm{~T}-\mathrm{C}$ & Silent & & 1 & 6.6 & Y \\
\hline 4940 & $C-T$ & Silent & & 1 & 6.6 & Y \\
\hline 4958 & $A-G$ & Silent & & 1 & 13.3 & Y \\
\hline 4991 & $\mathrm{G}-\mathrm{A}$ & Silent & 2 & 1 & 20.0 & Y \\
\hline 5004 & $\mathrm{~T}-\mathrm{C}$ & Silent & & 1 & 6.6 & Y \\
\hline 5027 & $\mathrm{C}-\mathrm{T}$ & Silent & 1 & & 6.6 & Y \\
\hline 5111 & $C-T$ & Silent & & 1 & 6.6 & Y \\
\hline 5147 & $\mathrm{G}-\mathrm{A}$ & Silent & 1 & 3 & 26.6 & Y \\
\hline 5320 & $C-T$ & $\mathrm{~T}-\mathrm{I}$ & 1 & 1 & 13.3 & Y \\
\hline 5331 & $C-A$ & $\mathrm{P}-\mathrm{H}$ & 1 & & 6.6 & Y \\
\hline 5351 & $A-G$ & Silent & 2 & 1 & 20.0 & Y \\
\hline \multicolumn{7}{|l|}{ ATPase 6 gene } \\
\hline 8697 & $\mathrm{G}-\mathrm{A}$ & Silent & 1 & & 6.6 & Y \\
\hline 8701 & $A-G$ & $\mathrm{~T}-\mathrm{A}$ & 1 & 6 & 46.6 & Y \\
\hline 8860 & $A-G$ & $\mathrm{~T}-\mathrm{A}$ & 1 & 6 & 46.6 & Y \\
\hline 9075 & $C-T$ & Silent & 1 & 2 & 13.3 & Y \\
\hline 9148 & $\mathrm{~T}-\mathrm{C}$ & Silent & & 1 & 6.6 & Y \\
\hline \multicolumn{7}{|c|}{ Total mutation numbers $=31$} \\
\hline
\end{tabular}

$Y$ the mutation proven by www.mitomap.org, $X$ novel mutation

sharing between the two groups. One SNP of deletion type at nucleotide number 4613 appeared in the two groups.

In addition, in the MT-ATPase6 gene, five mutations were found at different nucleotide positions in the normozoospermia and asthenozoospermia samples after alignment (Fig. 6). Three transition mutations were identified in both two groups, A8701G, A8860G, and C9075T, and G8697A appeared in normozoospermia and $\mathrm{T} 9148 \mathrm{C}$ in asthenozoospermia.
The transition mutations involve the substitution of either a purine for a purine or a pyrimidine for a pyrimidine (i.e., $\mathrm{A}>\mathrm{G}, \mathrm{G}>\mathrm{A}, \mathrm{C}>\mathrm{T}$, or $\mathrm{T}>\mathrm{C}$ ). Out of the thirty-one (31) nucleotide changes observed, only ten (10) mutations led to the amino acid change in which four have a deleterious effect, four are benign, and two mutations have conflicting results about effectiveness. T3398C, T3821C, G4048A, Ins T4169, T4216C, A4767G, C5320T, C5331A, A8701G, and A8860G caused a change from methionine to threonine, 
ND1 NC 012920 ND1 NORMOZOOSPERMIA ND1 ASTHENOZOOSPERMIA

ND1 NC 012920.1

ND1 NORMOZOOSPERMIA

ND1 ASTHENOZOOSPERMIA

ND1 NC 012920.1

ND1 NORMOZOOSPERMIA

ND1 ASTHENOZOOSPERMIA

ND1 NC 012920.1

ND1 NORMOZOOSPERMIA

ND1 ASTHENOZOOSPERMIA

ND1 NC_012920.1

ND1 NORMOZOOSPERMIA

ND1 ASTHENOZOOSPERMIA

ND1 NC 012920.1

ND NORM̄OZOOSPERMIA

ND1 ASTHENOZOOSPERMIA

ND1 NC_012920.1

ND1 NORMOZOOSPERMIA

ND1 ASTHENOZOOSPERMIA

ND1 NC_012920.1

ND1 NORMOZOOSPERMIA

ND1 ASTHENOZOOSPERMIA

ND1 NC 012920.1

ND1 NORMOZOOSPERMIA

ND1 ASTHENOZOOSPERMIA

ND1 NC_012920.1

ND1 NORMOZOOSPERMIA

ND1ASTHENOZOOSPERMIA

Fig. 4 The sequence alignment of the ND1 gene of normozoospermia and asthenozoospermia samples with reference sequence obtained from

the NCBI database (accession number: NC_012920.1) by the BioEdit software

CCAACCTCCTACTCCTCATTGTACCCATTCTAATCGCAATGGCATTCCTAATGCTTACCGAACGAAAAATCTAGGCTATATACAACTACGCAAAGGCC

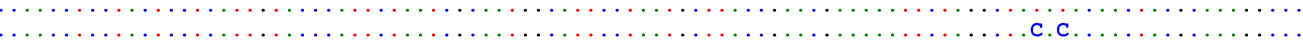
CAACGTTGTAGGCCCCTACGGGCTACTACAACCCTTCGCTGACGCCATAAAACTCTTCACCAAAGAGCCCCTAAAACCCGCCACATCTACCATCACCCTC

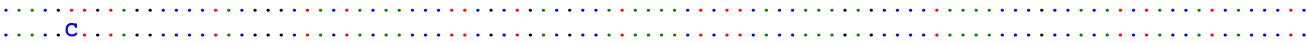

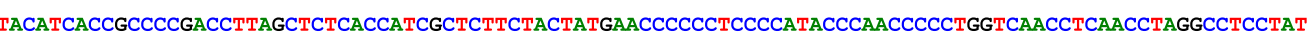
. TTATTCTAGCCACCTCTAGCCTAGCCGTTTACTCAATCCTCTGATCAGGGTGAGCATCAAACTCAAACTACGCCCTGATCGGCGCACTGCGAGCAGTAGC ‥ CCAAACAATCTCATATGAAGTCACCCTAGCCATCATTCTACTATCAACATTACTAATAAGTGGCTCCTTTAACCTCTCCACCCTTATCACAACACAAGAA

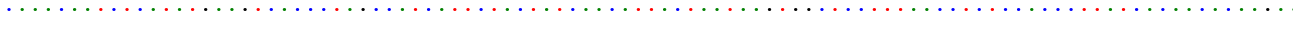
САССTCTGATTACTCCTGCCATCATGACCCTTGGCCATAATATGATTTATCTCCACACTAGCAGAGACCAACCGAACCCCCTTCGACCTTGCCGAAGGG

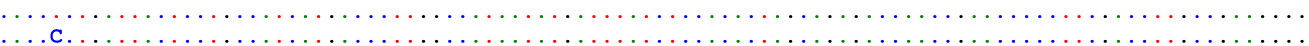
AGTCCGAACTAGTCTCAGGCTTCAACATCGAATACGCCGCAGGCCCCTTCGCCCTATTCTTCATAGCCGAATACACAAACATTATTATAATAAACACCCT CACCACTACAATCTTCCTAGGAACAACATATGACGCACTCTCCCCTGAACTCTACACAACATATTTTGTCACCAAGACCCTACTTCTAACCTCCCTGTTC

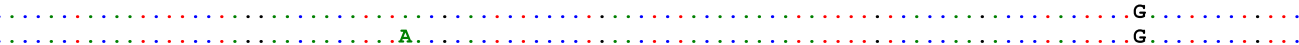
TTATGAATTCGAACAGCATACCCCCGATCCGCTACGACCAACTCATACACC-TCCTATGAAAAAACTTCCTACCACTCACCCTAGCATTACTTATATGA … TATGTCTCCATACCCATTACAATCTCCAGCATTCCC

c. . . . . . . . . . . . . . .

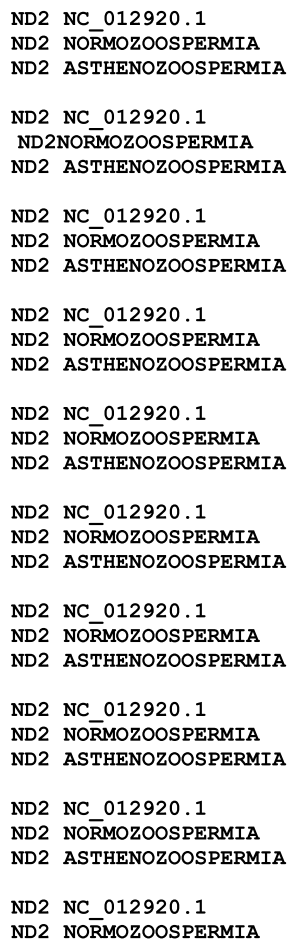

Fig. 5 The sequence alignment of the ND2 gene of normozoospermia and asthenozoospermia samples with reference sequence obtained from the NCBI database (accession number: NC_012920.1) by the BioEdit software 


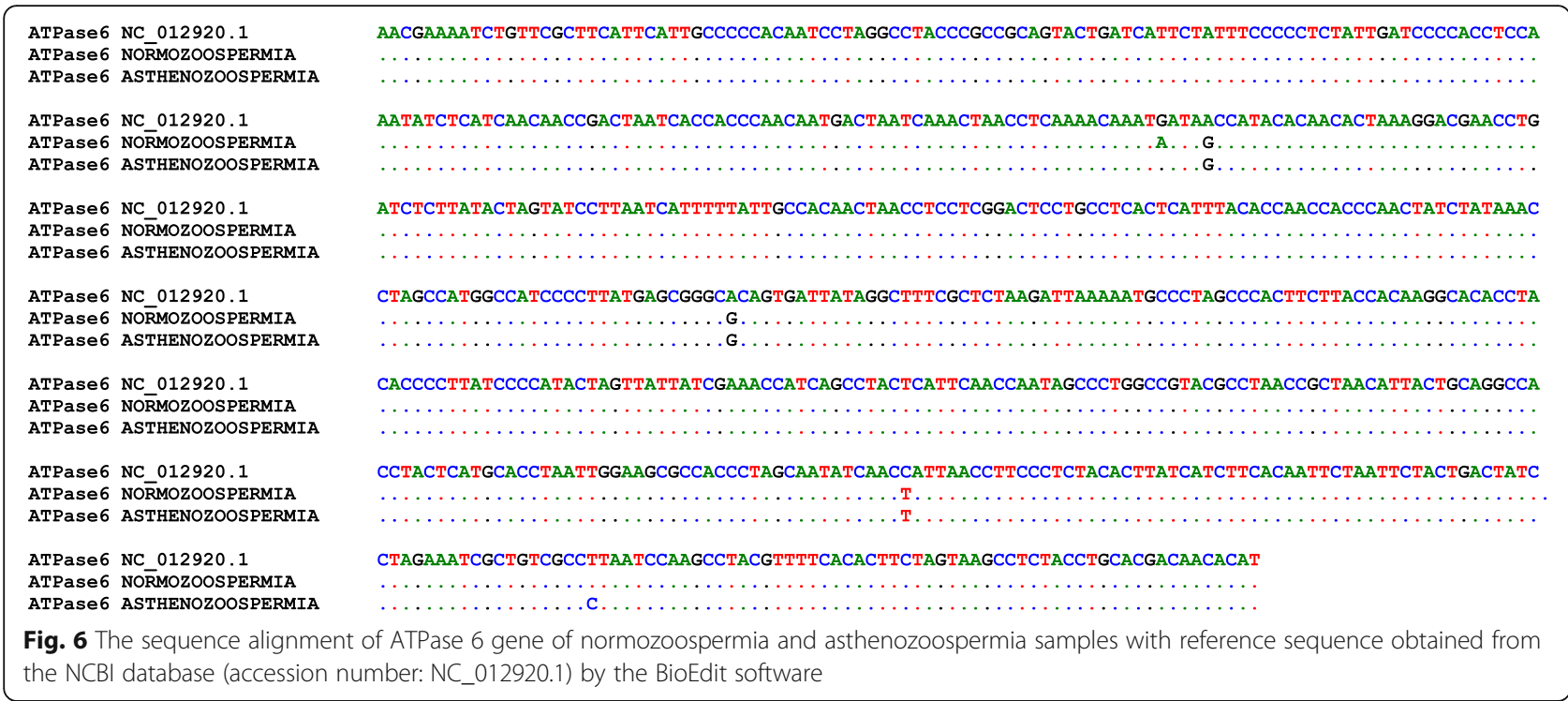

leucine to proline, aspartic acid to asparagine, leucine to proline, tyrosine to histidine, methionine to valine, threonine to isoleucine, proline to histidine, threonine to alanine, and threonine to alanine, respectively, as shown in Table 6.

All SNPs were proven by mitomap except three SNPs which were novel mutations; T3398C was a nonsynonymous mutation in which amino acid changed from methionine to threonine and had a deleterious effect on protein function. This mutation appeared only in asthenozoospermic samples which might cause low motility and infertility. The second mutation at position $\mathrm{T} 3423 \mathrm{C}$ also appeared in asthenozoospermia only but

Table 6 Predicted amino acid substitution effects in tested genes

\begin{tabular}{cll}
\hline Variant & PROVEAN score & Prediction (cutoff $=-\mathbf{2 . 5}$ ) \\
\hline ND1 & & \\
M15T & -5.188 & Deleterious \\
L156P & -3.248 & Deleterious \\
D232N & 1.312 & Neutral \\
L273P & -4.407 & Deleterious \\
Y288H & -0.759 & Neutral \\
ND2 & & \\
M33V & -0.092 & Neutral \\
T217I & 2.952 & Neutral \\
L221I & -1.829 & Neutral \\
ATPase 6 & & \\
T3A & -0.830 & Neutral \\
T56A & -4.013 & Deleterious \\
\hline
\end{tabular}

Italic amino acid indicates a mutual change in the normozoospermic and asthenozoospermic groups. Bold amino acid indicates a mutual change in the asthenozoospermic group only was a synonymous mutation. Deletion (A) at nucleotide position 4613 was a synonymous mutation and occurred in both groups.

\section{Discussion}

Male infertility is a medical and psychosocial global problem, and it accounts for approximately $40 \%$ of infertility in couples. Infertility itself affects about $7 \%$ of all couples attempting pregnancy [1]. Asthenozoospermia is a multifactor syndrome that affects approximately half of males with infertility. It could possibly be caused by defects in spermatozoa tail development or by energyproducing machinery defects that are essential to drive motility [32].

Oxidative stress has been recognized as an intermediary of male infertility through affecting sperm dysfunction. Although ROS minor amounts are necessary for sperm function, unbalanced levels can adversely impact the spermatozoa quality and their fertilizing capacity [33]. The data of the current inquiry noticed that asthenozoospermic infertile men were categorized with low total and progressive spermatozoa motility and a high percentage of sperm morphology and teratozoospermia index compared to normozoospermic men. In addition, there was a negative correlation between seminal plasma malondialdehyde (MDA) levels and sperm motility. This suggests that infertile patients undergo oxidative stressinduced lipid peroxidation, where malondialdehyde is an important marker for oxidative stress. A rise in MDA could be due to the increased generation of reactive oxygen species due to the excessive oxidative damage generated in infertile men. This oxygen species in turn can oxidize the lipids in the sperm membranes causing alterations in the sperm that may reduce fertility by affecting sperm motility [34]. Also, the resulting oxygen species 
usually manifests in a range of adverse sequelae that drive germ cell dysfunction and terminate their apoptotic demise [35]. This result is in accordance with the study of Masroor et al. [36]; they observed that the seminal plasma level of MDA was higher in asthenozoospermic males than in normozoospermic males. Regarding the relation between seminal MDA level and spermatozoa parameters in infertile men, $\mathrm{Al}$-azzawie et al. [37] revealed that higher seminal MDA levels were adversely related to progressive and non-progressive sperm motility and normal sperm morphology, whereas they were positively allied with immotile sperm. Nowicka-Bauer et al. [38] established that sperm dysfunction leading to asthenozoospermia, faulty mitochondria, and an associated reduction in the energy production that is vital to support normal movement have been identified as a common etiology. The assessment of seminal total antioxidant has been recommended as an appreciated tool to develop the estimation of sperm reproductive capacity and functional competence in infertile men. With this in mind, the result of total antioxidant capacity (TAC) analysis in the current study revealed significantly lower activity in asthenozoospermic. Our result was similar to Salimi et al. [39], and Hosen et al. [40] studies established that the total antioxidant capacity value in infertile men was lower than that in fertile men. In addition, Riaz et al .[41] and Ajina et al. [42] have shown the same results in asthenozoospermic men mentioning that low seminal total antioxidant capacity may be associated with a high concentration of ROS creation and might have a major role in the etiology of sperm abnormality. Fructose acts as an energy donor to the spermatozoa that break it down selectively and change it into energy. Fructose is reported to play an imperative role in sperm motility and concentration. Fructose is the main carbohydrate created in seminal plasma and looks crucial for sperm motility [28]. The result of seminal plasma fructose assessment indicates that the level of fructose concentration in asthenozoospermic patients was nonsignificantly decreased than in normozoospermic. Our results confirm those reported previously by Thi Trang et al. [28] that fructose seminal concentration has negative connections with sperm concentration and motility.

Sperm motility is a fundamental requirement to ensure male fertility. Correspondingly, a number of studies focused on the mitochondria, indicating their key role in cellular homeostasis and sperm motility [43]. Recent experiments in sperm physiology are concerning with the mitochondria as sperm health and fertility biomarker $[44,45]$. In addition, the mitochondrial sperm dysfunction is equally concerned in the pathogenesis of seminal oxidative stress that can be answerable in various cases of male idiopathic [46]. It has been confirmed that mtDNA base substitutions can really impact semen quality and motility [47]. Sperm mtDNA variations result in functionless proteins disturbing sperm motility which is strongly dependent on ATP biosynthesis which is carried out by the mitochondrial OXPHOS system [48]. The mtDNA rearrangement has been stated in asthenozoospermic patients [49]. The mtDNA variation has been established in the framework of various multifactorial diseases $[23,50,51]$. While mitochondrial mutations and their correlation to male infertility have been broadly investigated, there are still contradictions in data. Whereas numerous studies have informed association among male infertility have been broadly investigated, there are still contradictions in data. Whereas several studies have informed the association between male infertility and mtDNA mutations in certain genes [52-54], others did not $[55,56]$. The current study investigated the mtDNA mutations of asthenozoospermic men, and it provides the baseline data on mtDNA mutations among infertile and fertile Egyptian men for the first time. The results revealed that five nonsynonymous SNPs (nsSNPs) located at nucleotides T3398C, T3821C, G4048A, T4169TT, and T4216C in the ND1 gene that produced amino acid convert from methionine to threonine, leucine to proline, aspartic to asparagine, leucine to proline, and tyrosine to histidine, respectively. Secondary structure prediction of the proteins of $\mathrm{T} 3398 \mathrm{C}$ and $\mathrm{T} 3821 \mathrm{C}$ showed a detrimental change in protein function, so this mutation may cause sperm motility decline and male infertility. Mughal et al. [57] settled that the mtDNA mutations had a significant influence on sperm quality causing infertility by affecting various sperm motility parameters. Zhang et al. [58] reported that due to the low occurrence frequency and limited sample size, m C3398T showed a decreased risk of asthenozoospermia. The mitochondrial transition mutation T4216C was found only in normozoospermic men with a percentage of $14.2 \%$. While Khan et al. [59] and Stenson et al. [60] confirmed that there was a genetic mutation in the base substitutions that do change in the SNP T4216C position in fertile and subfertile men. It was observed in asthenozoospermic man and change synonym in tyrosine codon third position converting it from TAT to TAC. The non-synonymous (nsSNPs) are the greatest mutual genetic variation type. They can affect the protein function leading to an impact on human health [61].

Additionally, the present results displayed that subfertile patients had twelve mutual SNPs in the ND2 gene. Ten SNPs were synonymous (nine transition mutations, T4856C, C4940T, A4958G, T5004C, C5111T, A4769G, G4991A, G5147A, and A5351G) plus one deletion type at nucleotide (A) 4613. The other two mutations were non-synonymous at positions A4767G and C5320T. In addition, synonymous mutations (C7024T and C7891T) 
in COXI and COXII were recognized as $\mathrm{T}$ polymorphic sites in men with low sperm mobility [62]. The synonymous mutations found by Harris et al. [63] also showed $58 \%$ of subfertile men have reduced relative codon usage and 33\% with higher and $8.33 \%$ did not show any transformation in their relative codon usage. Likewise, additional synonymous mutations in the subfertile group were connected with reduced relative codon usage. All these findings recommended that synonymous codons with low frequency rate are more recurrent in subfertile men. The non-synonymous single nucleotide polymorphisms (nsSNPs) are the greatest mutual type of genetic variation. They can affect the protein function leading to an impact on human health compared with SNPs in other regions of the genome [61].

Zhang et al. [58] detected the mitochondrial mutations T4856C, C4940T, G4991A, and G5147A in the MT-ND2 gene of the total fertilization failure (TFF) group, but there were no significant differences in the frequencies of point heteroplasmic variants between the TFF and control. Also, no significant variation in the frequencies of mtDNA haplogroup D or G among the IVF fertilization failure and the normal groups. They conclude that no significant difference in the Han Chinese population but might affect other populations. Barbhuiya et al. [54] and Bimah [64] found that the non-synonymous transition mutation $A>G$ at nt 4769 was noticed in all the cases of both control and infertile groups.

Associating the present results with the earlier studies, one can find worthy evidence for applying the ATPase 6 gene in differentiating between fertile and infertile men [65]. The sequence of MT-ATPase 6 gene revealed a high frequency of nucleotide changes in asthenozoospermic men. Significant non-synonymous nucleotide mutations (nsSNPs) A8701G and A8860G were identified in the asthenozoospermic group with $75 \%$ changed from threonine to alanine, while synonymous (sSNPs) G8697A and C9075T were found in the normozoospermic group with $14 \%$, while the T9148C was observed in asthenozoospermic in leucine codon by $12.5 \%$.

These findings were agreed with that of Holyoake et al.'s [66] investigation on samples from New Zealand in sharing the non-synonymous sites G8860A. Our results agreed also with that of [53] in characterizing the non-synonymous sites A8701G and G8860A in oligoasthenozoospermic men. These mutations changed the amino acid from threonine to alanine and may affect sperm motility. Also, our results are comparable to the results of Kumar and Sangeetha [53] asserting that A8860G nucleotide substitution was present in infertile men with $91 \%$ and in control with $47 \%$. In addition, many authors found that base substitution reversed to our result at nucleotide 8860 (G to A) within ATPase 6, changing from an alanine to a threonine [55, 67]. Moreover, Barbhuiya et al. [54] observed the mutations
A4769G, A8702G, and A8860G in both fertile and infertile males. These notes suggest that these mutations might be prevalent mutations in the general population and not allied with male infertility. Bimah et al. [64] confirmed that the frequencies of occurrence of the mutations at nts 8860 and 8701 were a hundred percent (100\%) in both the normozoospermic and abnormospermic subjects. Elsanousi et al. [65] sequenced the ATPase subunit 6 mitochondrial genes (ATPase 6) for infertile and normal Saudi men to identify the SNPs associated with male infertility. Seven non-synonymous substitutions were obtained with 4 novel sites (C8684T, G8860A, C8876T, and G9055A) in asthenozoospermic men. It could be recognized that there was a link between ATPase 6 substitutions and male sterility.

Mitochondrial genome nucleotide substitutions have a relation with a variety of metabolic pathologies; nevertheless, investigation of the outcome of definite mtDNA genotypes is continuous. mtDNA alterations have specific importance for reproductive characters; subsequently, they are predicted to have deep impacts on male exact procedures because of the exact maternal inheritance of mtDNA [21].

Contrary to the aforesaid evidence, Pereira et al. [6] analyzed the complete mtDNA of asthenozoospermic patients and whole mitogenomes of teratoasthenozoospermic males and confirmed no association between male infertility and mitogenomes. Similarly, Palanichamy and Zhang [56] supposed that no relationship between the mtDNA substitutions and infertility in males. These authors considered the published data are the misleading application of the mitochondrial polymorphisms in male sterility diagnosis.

The malfunctioning protein subunits due to mutated mtDNA, when collected with nuclear-encoded subunits, lead to respiratory enzyme anomaly [68]. Spermatozoa with mutant mtDNA are producing less efficient ATP and generate extra ROS that may impair the mitochondria and mtDNA causing definitive energy crisis, motility, and fertility decline $[9,69]$.

\section{Conclusion}

In summary, the first study on the Egyptian population demonstrated that the incidences of the mtDNAs with the ND1, ND2, and ATPase6 genes are positively associated with spermatozoa motility and fertility. Although the small sample size and focusing on the asthenozoospermic Egyptian population, it was hard to confirm the effect of mitochondrial mutations in male infertility. The results showed scientific indications evidenced that there is a connection between mitochondrial mutations and infertility in some tested cases. Additional studies would comprise a more patient number, genes, and SNPs which will eventually aid us to realize the individual genetic factors influence the progress of male infertility. 


\section{Abbreviations}

ATP: Adenine triphosphate; ATPase6: ATP synthase membrane subunit 6 gene; bp: Base pair; dATP: Deoxyadenosine triphosohate; ETC: Electron transport chain; G: Guanine or guanosine; glycine; gm: Grams; h: Hours; $\mathrm{H}_{2} \mathrm{O}_{2}$ : Hydrogen peroxide; Ma: Milliampere; MDA: Malondialdehyde; MIM: Mitochondrial membrane; min: Minutes; mRNA: Messenger ribonucleic acid; mtDNA: Mitochondrial deoxyribonucleic acid; NADPH: Nicotinamide adenine dinucleotide phosphate; NCBI: National Centre of Biotechnology Information; ND1: NADH dehydrogenase 1; ND2: NADH dehydrogenase 2; nDNA: Nuclear deoxyribonucleic acid; ng: Nanogram; nmol: Nanomole; np: Nucleotide position; nt: Nucleotide; OAT: Oligoasthenoteratozoospermia; OS: Oxidative stress; OXPHOS: Oxidative phosphorylation system; PCR: Polymerase chain reaction; PR: Progressively; PUFAs: Polyunsaturated fatty acids; RNA: Ribonucleic acid; ROS: Reactive oxygen species; rRNAs: Ribosomal ribonucleic acid; SDI: Sperm deformative index SEM: Slandered error of the mean; SNPs: Single nucleotide polymorphisms; sSNPs: Synonymous single nucleotide polymorphisms; T: Thymine or thymidine; threonine; TAC: Total antioxidant capacity; Taq DNA: Thermus aquaticus DNA; TBA: Thiobarbituric acid; Tm: Melting temperature; tRNAs: Transfer ribonucleic acid; U: Unit; UV: Ultraviolet

\section{Acknowledgements}

This work is of the Ph.D. thesis of student Mohamed Mahmoud Abdel Rahman Mohamed. We appreciate the role of the National Research Centre, Cairo, Egypt, in funding this thesis.

\section{Authors' contributions}

$\mathrm{AIE}, \mathrm{MSH}$, and MMA conceived and designed the experiments. MMA performed the experiments and analyzed the data. MKA contributed by providing samples. AIE, SAA, and NHA wrote and revised the paper. The final manuscript was reviewed and approved by all authors.

\section{Funding}

This research was supported by the National Research Centre.

\section{Availability of data and materials}

The data and materials are available.

\section{Ethics approval and consent to participate}

The manuscript was approved by the Ethics Committee of the National Research Centre (Approval No. 16/455). The patients' consent form is available.

\section{Consent for publication}

Not applicable

\section{Competing interests}

The authors have no competing interest to declare.

\section{Author details}

${ }^{1}$ Cell Biology Dept. , Division of Genetic Engineering and Biotechnology Research, National Research Centre, 33 El Bohouth St., Dokki, P.O.12622, Giza, Egypt. ${ }^{2}$ Zoology Dept., Faculty of Science, Ain Shams University, Cairo, Egypt. ${ }^{3}$ Surgery Andrology and infertility Department, Faculty of Medicine, Cairo University, Cairo, Egypt.

\section{Received: 5 October 2020 Accepted: 25 December 2020}

Published online: 18 January 2021

\section{References}

1. Lotti F, Maggi M (2015) Ultrasound of the male genital tract in relation to male reproductive health. Hum Reprod Update 21(1):56-83. https://doi.org/ 10.1093/humupd/dmu042

2. Cooper TG, Noonan E, Von Eckardstein S, Auger J, Baker HW, Behre HM, Haugen TB, Kruger T, Wang C (2009) World Health Organization reference values for human semen characteristics. Human Reprod Update 16(3):231245. https://doi.org/10.1093/humupd/dmp048

3. Khalil AA, Hussien MH, Sarhan ME (2011) Oxidative stress induces idiopathic infertility in Egyptian males. African J Biotech 11(6):1516-1522. https://doi. org/10.5897/ajb11.1745
4. Holt W, Van Look KJW (2004) Concepts in sperm heterogeneity, sperm selection and sperm competition as biological foundations for laboratory test of semen quality. Reproduction 127(5):527-535. https://doi.org/10.1530/ rep. 1.00134

5. Zheng J, Lu Y, Qu X et al (2016) Decreased sperm motility retarded ICSI fertilization rate in severe oligozoospermia but good-quality embryo transfer had achieved the prospective clinical outcomes. PLoS One 11(9). https://doi.org/10.1371/journal.pone.0163524

6. Pereira R, Sa R, Barros A, Sousa M (2017) Major regulatory mechanisms involved in sperm motility. Asian J Androl 19(1):5-14. https://doi.org/10. 4103/1008-682X.167716

7. Srivastava S (2016) Emerging therapeutic roles for NAD + metabolism in mitochondrial and age-related disorders. Clin Transl Med 5(1):25. https://doi. org/10.1186/s40169-016-0104-7

8. Demain LAM, Conway GS, Newman WG (2017) Genetics of mitochondrial dysfunction and infertility. Clin Genet 91(2):199-207. https://doi.org/10.1111/ cge.12896

9. Rajender S, Rahul P, Mahdi AA (2010) Mitochondria, spermatogenesis and male infertility. Mitochondrion 10(5):419-428. https://doi.org/10.1016/j.mito. 2010.05.015

10. Tuppen HAL, Blakely EL, Turnbull DM, Taylor RW (2010) Mitochondrial DNA mutations and human disease. Biochim Biophys Acta Bioenerg. 1797(2):113128. https://doi.org/10.1016/j.bbabio.2009.09.005

11. Bar-Yaacov D, Blumberg A, Mishmar D (2012) Mitochondrial-nuclear coevolution and its effects on OXPHOS activity and regulation. Biochim Biophys Acta Gene Regul Mech 1819(9-10):1107-1111. https://doi.org/10. 1016/j.bbagrm.2011.10.008

12. Alexeyev M, Shokolenko I, Wilson G, LeDoux S (2013) The maintenance of mitochondrial DNA integrity - critical analysis and update. Cold Spring Harb Perspect Biol 5(5). https://doi.org/10.1101/cshperspect.a012641

13. Lee SR, Han J (2017) Mitochondrial nucleoid: shield and switch of the mitochondrial genome. Oxid Med Cell Longev. https//doi.org/10.1155/2017/8060949

14. Gorman GS, Grady JP, Turnbull DM (2015) Mitochondrial donation - how many women could benefit? N Engl J Med 372(9):885-887. https://doi.org/ 10.1056/NEJMc1500960

15. Gorman GS, Schaefer AM, Ng Y et al (2015) Prevalence of nuclear and mitochondrial DNA mutations related to adult mitochondrial disease. Ann Neurol 77(5):753-759. https://doi.org/10.1002/ana.24362

16. Pelliccione F, Verratti V, D'Angeli A et al (2011) Physical exercise at high altitude is associated with a testicular dysfunction leading to reduced sperm concentration but healthy sperm quality. Fertil Steril 96(1):28-33. https://doi. org/10.1016/j.fertnstert.2011.03.111

17. John JCST, Jokhi RP, Barratt CLR (2005) The impact of mitochondrial genetics on male infertility. Int J Androl 28(2):65-73. https://doi.org/10.1111/ j.1365-2605.2005.00515.x

18. Jodar M, Kalko S, Castillo J, Ballescà JL, Oliva R (2012) Differential RNAs in the sperm cells of asthenozoospermic patients. Hum Reprod 27(5):14311438. https://doi.org/10.1093/humrep/des021

19. Colagar AH, Karimi F, Jorsaraei SGA (2013) Correlation of sperm parameters with semen lipid peroxidation and total antioxidants levels in astheno- and oligoasheno-teratospermic men. Iran Red Crescent Med J 15(9):780-785. https://doi.org/10.5812/ircmj.6409

20. Yee WKW, Sutton KL, Dowling DK (2013) In vivo male fertility is affected by naturally occurring mitochondrial haplotypes. Curr Biol. 23(2):R55-R56. https://doi.org/10.1016/j.cub.2012.12.002

21. Tourmente $\mathrm{M}$, Hirose $\mathrm{M}$, Ibrahim $\mathrm{S}$ et al (2017) mtDNA polymorphism and metabolic inhibition affect sperm performance in conplastic mice. Reproduction 154(4):341-354. https://doi.org/10.1530/REP-17-0206

22. Patron J, Serra-Cayuela A, Han B, Li C, Wishart DS (2019) Assessing the performance of genome-wide association studies for predicting disease risk. PLoS One 14(12). https://doi.org/10.1371/journal.pone.0220215

23. Salas A, Martinón-Torres F, Gómez-Carballa A (2016) 'Infertile' studies on mitochondrial DNA variation in asthenozoospermic Tunisian men. Biochem Biophys Reports 8:114-119. https://doi.org/10.1016/j.bbrep.2016.08.002

24. Al Zoubi MS, Al-Batayneh K, Alsmadi M et al (2020) 4,977-bp human mitochondrial DNA deletion is associated with asthenozoospermic infertility in Jordan. Andrologia 52(1). https://doi.org/10.1111/and.13379

25. Talebi E, Karimian M, Nikzad H (2018) Association of sperm mitochondrial DNA deletions with male infertility in an Iranian population. Mitochondrial DNA Part A DNA Mapp Seq Anal 29(4):615-623. https://doi.org/10.1080/ 24701394.2017.1331347 
26. World Health Organization (2010) WHO laboratory manual for the examination and processing of human semen, 5th edn. World Health Organization, Geneva

27. Kamal AAM, Gomaa A, El Khafif M, Hammad AS (1989) Plasma lipid peroxides among workers exposed to silica or asbestos dusts. Environ Res 49(2):173-180. https://doi.org/10.1016/S0013-9351(89)80062-3

28. Thi Trang N, Sang TT, Hoang N, Gia Khanh NT, Duc TT (2018) Assessment of the level of seminal zinc and fructose concentration in seminal plasma of Vietnamese infertile men. MOJ Bioorganic Org Chem 2(4). https://doi.org/10. 15406/mojboc.2018.02.00079

29. Foreman D, Gaylor L, Evans E, Trella C (1973) A modification of the Roe procedure for determination of fructose in tissues with increased specificity. Anal Biochem 56(2):584-590. https://doi.org/10.1016/0003-2697(73)90225-X

30. Koracevic D, Koracevic G, Djordjevic V, Andrejevic S, Cosic V (2001) Method for the measurement of antioxidant activity in human fluids. J Clin Pathol 54(5):356-361. https://doi.org/10.1136/jcp.54.5.356

31. Güney Al, Javadova D, Kirac D et al (2012) Detection of Y chromosome microdeletions and mitochondrial DNA mutations in male infertility patients. Genet Mol Res 11(2):1039-1048. https://doi.org/10.4238/2012.April. 27.2

32. Baklouti-Gargouri S, Ghorbel M, Ben Mahmoud A et al (2013) Mitochondrial DNA mutations and polymorphisms in asthenospermic infertile men. Mol Biol Rep 40(8):4705-4712. https://doi.org/10.1007/s11033-013-2566-7

33. Agarwal A, Virk G, Ong C, du Plessis SS (2014) Effect of oxidative stress on male reproduction. World J Mens Health 32(1):1. https://doi.org/10.5534/ wjmh.2014.32.1.1

34. Aitken RJ, Baker MA, De luliis GN, Nixon B (2010) New insights into sperm physiology and pathology. Handb Exp Pharmacol 198:99-115. https://doi. org/10.1007/978-3-642-02062-9_7

35. Walters JLH, de luliis GN, Nixon B, Bromfield EG (2018) Oxidative stress in the male germline: a review of novel strategies to reduce 4-hydroxynonenal production. Antioxidants 7(10). https://doi.org/10.3390/antiox7100132

36. Masroor S, Muneshwar JN, Zingade US (2013) Estimation of seminal mda levels in infertility patients. J Dent Med Sci 4(4):18-23

37. Al-azzawie HF, Naeim M, Saleman ED (2014) Evaluation of enzymatic and non-enzymatic antioxidant status in seminal plasma of Iraqi infertile men. Int J Adv Res 2(06):158-167

38. Nowicka-Bauer K, Lepczynski A, Ozgo M et al (2018) Sperm mitochondrial dysfunction and oxidative stress as possible reasons for isolated asthenozoospermia. J Physiol Pharmacol 69(3). https://doi.org/10.26402/jpp. 2018.3.05

39. Salimi S, Fazeli F, Khosravi P, Nabizadeh S (2016) Association of seminal plasma total antioxidant capacity and malondialdehyde levels with sperm parameters in infertile men with varicocele. Avicenna J Med Biochem In Press (In Press). https://doi.org/10.17795/ajmb.33540

40. Hosen MB, Islam MR, Begum F, Kabir Y, Howlader MZH (2015) Oxidative stress induced sperm DNA damage, a possible reason for male infertility. Iran J Reprod Med 13(9):525-532

41. Riaz M, Mahmood Z, Shahid M et al (2016) Impact of reactive oxygen species on antioxidant capacity of male reproductive system. Int $J$ Immunopathol Pharmacol 29(3):421-425. https://doi.org/10.1177/ 0394632015608994

42. Ajina T, Sallem A, Haouas Z, Mehdi M (2017) Total antioxidant status and lipid peroxidation with and without in vitro zinc supplementation in infertile men. Andrologia 49(7). https://doi.org/10.1111/and.12703

43. Ahmed Z, Shoaib Khan M, Khan A, UI Haq A, Ur Rahman J (2010) Seminal fructose in various classes of infertile patients, vol 6

44. Barbagallo F, La Vignera S, Cannarella R, Aversa A, Calogero AE, Condorelli RA (2020) Evaluation of sperm mitochondrial function: a key organelle for sperm motility. J Clin Med 9(2):363. https://doi.org/10.3390/jcm9020363

45. Darr CR, Varner DD, Teague S, Cortopassi GA, Datta S, Meyers SA (2016) Lactate and pyruvate are major sources of energy for stallion sperm with dose effects on mitochondrial function, motility, and ROS production. Biol Reprod 95(2). https://doi.org/10.1095/biolreprod.116.140707

46. Moraes CR, Meyers S (2018) The sperm mitochondrion: organelle of many functions. Anim Reprod Sci 194:71-80. https://doi.org/10.1016/j.anireprosci. 2018.03.024

47. La Vignera S, Condorelli RA, Duca Y et al (2019) FSH therapy for idiopathic male infertility: four schemes are better than one. Aging Male. Published online. https://doi.org/10.1080/13685538.2019.1590696
48. Xavier MJ, Nixon B, Roman SD, Scott RJ, Drevet JR, Aitken RJ (2019) Paternal impacts on development: identification of genomic regions vulnerable to oxidative DNA damage in human spermatozoa. Hum Reprod 34(10):18761890. https://doi.org/10.1093/humrep/dez153

49. Thangaraj K, Joshi MB, Reddy AG, Rasalkar AA, Singh L (2003) Sperm mitochondrial mutations as a cause of low sperm motility. J Androl 24(3): 388-392. https://doi.org/10.1002/j.1939-4640.2003.tb02687.x

50. Chari MG, Colagar AH, Bidmeshkipour A (2015) A novel large-scale deletion of the mitochondrial DNA of spermatozoa of men in north Iran. Int J Fertil Steril 8(4):453-462. https://doi.org/10.22074/ijfs.2015.4185

51. Achilli A, Olivieri A, Pala M et al (2011) Mitochondrial DNA backgrounds might modulate diabetes complications rather than T2DM as a whole. PLoS One 6(6). https://doi.org/10.1371/journal.pone.0021029

52. Alvarez-lglesias V, Mosquera-Miguel A, Cusco I, Carracedo Á, Perez-Jurado LA, Salas A (2011) Reassessing the role of mitochondrial DNA mutations in autism spectrum disorder. BMC Med Genet 12:50. https:/doi.org/10.1186/1471-2350-12-50

53. Kumar DP, Sangeetha N (2009) Mitochondrial DNA mutations and male infertility. Indian J Hum Genet 15(3):93-97. https://doi.org/10.4103/09716866.60183

54. Barbhuiya PN, Gogoi A, Ahmed G, Mahanta R (2016) Prevalence of mitochondrial DNA nucleotide substitution mutations in male infertile cases of Northeast India research article prevalence of mitochondrial DNA nucleotide substitution mutations in male infertile cases of Northeast India (June)

55. Pereira L, Gonçalves J, Bandelt HJ (2008) Mutation C11994T in the mitochondrial ND4 gene is not a cause of low sperm motility in Portugal. Fertil Steril 89(3):738-741. https://doi.org/10.1016/j.fertnstert.2007.03.048

56. Palanichamy MG, Zhang YP (2011) Identifying potential pitfalls in interpreting mitochondrial DNA mutations of male infertility cases. Indian J Med Res 134(10):447-451

57. Mughal IA, IIfan A, Jahan S, Hameed A (2017) Male infertility is significantly associated with multiple deletions in an 8.7-kb segment of sperm mtDNA in Pakistan. Turkish J Med Sci 47(3):928-933. https://doi.org/10.3906/sag-1606-52

58. Zhang Y, Zhao Y, Wen S, Yan R, Yang Q, Chen H (2017) Associations of mitochondrial haplogroups and mitochondrial DNA copy numbers with end-stage renal disease in a Han population. Mitochondrial DNA Part A DNA Mapping Seq Anal 28(5):725-731. https://doi.org/10.1080/24701394. 2016.1177038

59. Khan AUH, Rathore MG, Allende-Vega N et al (2016) Human leukemic cells performing oxidative phosphorylation (OXPHOS) generate an antioxidant response independently of reactive oxygen species (ROS) production. EBioMedicine 3:43-53. https://doi.org/10.1016/j.ebiom.2015.11.045

60. Stenson PD, Mort M, Ball EV et al (2017) The Human Gene Mutation Database: towards a comprehensive repository of inherited mutation data for medical research, genetic diagnosis and next-generation sequencing studies. Hum Genet 136(6):665-677. https://doi.org/10.1007/s00439-017-1779-6

61. Ng PC, Henikoff S (2006) Predicting the effects of amino acid substitutions on protein function. Annu Rev Genomics Hum Genet 7(1):61-80. https://doi. org/10.1146/annurev.genom.7.080505.115630

62. Ruiz-Pesini E, Lapeña AC, Díez-Sánchez C et al (2000) Human mtDNA haplogroups associated with high or reduced spermatozoa motility. Am J Hum Genet 67(3):682-696. https://doi.org/10.1086/303040

63. Harris TP, Gomas KP, Weir F et al (2006) Molecular analysis of polymerase gamma gene and mitochondrial polymorphism in fertile and subfertile men. Int J Androl 29(3):421-433. https://doi.org/10.1111/j.1365-2605.2005. 00633.x

64. Bimah B (2016) Common mitochondrial DNA mutations among infertile males on referral to the Korle-Bu teaching hospital in partial fulfilment of the requirements for the award of a master of philosophy degree in medical biochemistry

65. Elsanousi SAM, Javed M, Sufyan H, Amer SAM (2020) Forensic relationship between ATP6 gene and sperm motility in a Saudi population. Am J Biochem Biotechnol 16(1):15-24. https://doi.org/10. 3844/ajbbsp.2020.15.24

66. Holyoake AJ, McHugh P, Wu M et al (2001) High incidence of single nucleotide substitutions in the mitochondrial genome is associated with poor semen parameters in men. Int J Androl 24(3):175-182. https://doi.org/ 10.1046/.j.1365-2605.2001.00292.x

67. Aikhionbare FO, Mehrabi S, Kumaresan K et al (2007) Mitochondrial DNA sequence variants in epithelial ovarian tumor subtypes and stages. J Carcinog 6:1. https://doi.org/10.1186/1477-3163-6-1 
68. Gashti NG, Salehi Z, Madani AH, Dalivandan ST (2014) 4977-bp

mitochondrial DNA deletion in infertile patients with varicocele. Andrologia 46(3):258-262. https://doi.org/10.1111/and.12073

69. Chen $\mathrm{Q}$, Zhang R, Li W et al (2013) The protective effect of grape seed procyanidin extract against cadmium-induced renal oxidative damage in mice. Environ Toxicol Pharmacol 36(3):759-768. https://doi.org/10.1016/j. etap.2013.07.006

\section{Publisher's Note}

Springer Nature remains neutral with regard to jurisdictional claims in published maps and institutional affiliations.

Submit your manuscript to a SpringerOpen ${ }^{\odot}$ journal and benefit from:

- Convenient online submission

Rigorous peer review

- Open access: articles freely available online

High visibility within the field

- Retaining the copyright to your article

Submit your next manuscript at $\boldsymbol{\wedge}$ springeropen.com 